\title{
BMJ Open Patient and practice characteristics predicting attendance and completion at a specialist weight management service in the UK: a cross-sectional study
}

\author{
David N Blane, ${ }^{1}$ Philip McLoone, ${ }^{2}$ David Morrison, ${ }^{2}$ Sara Macdonald, ${ }^{1}$ \\ Catherine A O'Donnell ${ }^{1}$
}

To cite: Blane DN, McLoone P, Morrison D, et al. Patient and practice characteristics predicting attendance and completion at a specialist weight management service in the UK: a crosssectional study. BMJ Open 2017;7:e018286. doi:10.1136/ bmjopen-2017-018286

- Prepublication history for this paper is available online. To view these files, please visit the journal online (http://dx.doi org/10.1136/bmjopen-2017018286).

Received 19 June 2017 Revised 31 August 2017 Accepted 11 September 2017

CrossMark

${ }^{1}$ General Practice and Primary Care, Institute of Health and Wellbeing, University of Glasgow, Glasgow, UK

${ }^{2}$ Public Health, Institute of Health and Wellbeing, University of Glasgow, Glasgow, UK

Correspondence to

Professor Catherine A 0'Donnell; Kate.0'Donnell@glasgow.ac.uk

\section{ABSTRACT}

Objective To determine the association between patient and referring practice characteristics and attendance and completion at a specialist health service weight management service (WMS).

Design Cross-sectional study.

Setting Regional specialist WMS located in the West of Scotland.

Participants 9677 adults with obesity referred between 2012 and 2014; 3250 attending service and 2252 completing.

Primary and secondary outcome measures Primary outcome measure was attendance at the WMS; secondary outcome was completion, defined as attending four or more sessions.

Analysis Multilevel binary logistic regression models constructed to determine the association between patient and practice characteristics and attendance and completion.

Results Approximately one-third of the 9677 obese adults referred attended at least one session $(n=3250$, $33.6 \%$ ); only 2252 (23\%) completed by attending four or more sessions. Practice referrals ranged from 1 to 257 . Patient-level characteristics were strongest predictors of attendance; odds of attendance increased with age (OR $4.14,95 \% \mathrm{Cl} 3.27$ to 5.26 for adults aged $65+$ compared with those aged 18-24), body mass index (BMI) category (OR $1.83,95 \% \mathrm{Cl} 1.56$ to 2.15 for BMl 45+ compared with BMI 30-35) and increasing affluence (OR 1.96, 95\% Cl 1.17 to 3.28$)$. Practice-level characteristics most strongly associated with attendance were being a non-training practice, having a larger list size and not being located in the most deprived areas.

Conclusions There was wide variation in referral rates across general practice, suggesting that there is still much to do to improve engagement with weight management by primary care practitioners. The high attrition rate from referral to attendance and from attendance to completion suggests ongoing barriers for patients, particularly those from the most socioeconomically deprived areas. Patient and practice-level characteristics can help us understand the observed variation in attendance at specialist WMS following general practitioner (GP) referral and the underlying explanations for these differences merit further investigation.

\section{Strengths and limitations of this study}

- Explores the predictors of attendance and completion at adult weight management services (WMS) taking account of both individual patient factors and referring practice characteristics.

- Data were obtained from a large urban WMS between 2012 and 2014, with data on referrals, attendances and completion.

- Patient-level data linked to the characteristics of the 262 general practices in the Health Board area who make referrals to the service.

- There were no available data on weight loss outcomes in this study population, which is a limitation.

\section{INTRODUCTION}

Obesity is a major global public health concern with considerable health and economic consequences. ${ }^{1-3}$ International guidelines recommend that practitioners opportunistically identify overweight and obese patients, with the aim of encouraging weight loss. ${ }^{45}$ Much of this work takes place in primary care. ${ }^{6}$ However, obesity remains undertreated in primary care, ${ }^{78}$ and patient identification is only the first part of the journey. Current UK policy recommends a comprehensive tiered approach to weight management (box), ${ }^{59}$ but there is marked variation in referrals to weight management services (WMS) from primary care, and a high attrition rate between referral and attendance. ${ }^{10}$ The reasons for this are unclear. One factor is patient characteristics, such as socioeconomic status, with more affluent patients more likely to be referred. ${ }^{11}$ Previous research on referral variation has suggested that only $40 \%$ of variation can be explained by patient characteristics. ${ }^{12}$ Practitioner factors such as views of risk and clinical experience, as well as system factors, such as distance to 


\section{Box Tiered approach to weight management}

Tier 1: Population wide health improvement work (eg, prehealthcare lifestyle advice, community pharmacies and commercial weight management).

Tier 2: Lifestyle interventions delivered in the community (eg, healthy eating, exercise referral and community dietetic service).

Tier 3: Specialist weight management services.

Tier 4: Bariatric surgery.

services, also explain some of the variation observed in referral rates to secondary care. ${ }^{12} 13$ These factors may also contribute to an individual's likeliness to both attend a service and complete the course of treatment on offereach of these are important issues in weight management, where patients are being asked to make significant changes to their lifestyle and behaviour.

Several previous studies have explored individual practitioner views on referral to WMS. ${ }^{14-16}$ Issues raised included patient factors such as motivation and expectations, and practitioner factors such as previous experience and pessimism. However, there are no quantitative studies that have explored the predictors of attendance at WMS taking account of both individual factors and practice characteristics. The aim of this study, therefore, was to use individual and practice-level data to explore predictors of attendance and completion at a specialist WMS (tier 3), using multilevel binary logistic regression models.

\section{METHODS}

\section{Setting}

The Glasgow and Clyde Weight Management Service (GCWMS) is the most well-established, well-funded and well-evaluated National Health Service (NHS)-based non-commercial service in Scotland. ${ }^{101718}$ It is a multicomponent weight management programme, which includes structured lifestyle advice, underpinned by psychological approaches, and is available to patients aged 18 years and over with complex obesity (defined as body mass index (BMI) of $\geq 30 \mathrm{~kg} / \mathrm{m}^{2}$ with obesity-related comorbidities or BMI of $\geq 35 \mathrm{~kg} / \mathrm{m}^{2}$ alone).$^{10}$ For those patients with obesity that do not meet the eligibility criteria (ie, BMI $30-35 \mathrm{~kg} / \mathrm{m}^{2}$ without weight-related comorbidities), general practitioners (GPs) and practice nurses can signpost patients to healthy eating classes or physical activity resources, where available.

Eligible patients are referred electronically by their GP or practice nurse (a small proportion come from secondary care referrals) and are required to 'opt in' to the service within 2 weeks of referral. They are then seen (usually within 1 or 2 months) by a dietitian at an initial assessment, who helps to direct them to an appropriate group or professional. Some patients (eg, those with possible binge eating disorder) may receive further input from a clinical psychologist or physiotherapist. Most patients are seen in groups of no more than 16 people, led by a NHS dietitian, at a number of venues throughout Glasgow and Clyde. Phase 1 of the intervention includes nine sessions (90 min each) delivered fortnightly over a 16-week period. Further treatment options, including prescribed low-calorie diet, pharmacotherapy (orlistat) and bariatric surgery, are only available after completion of phase 1 of the programme. A previous paper has described the service and its weight loss outcomes in more detail. ${ }^{10}$

It receives the majority of its referrals from the 262 general practices in the NHS Greater Glasgow and Clyde (GGC) health board area, with a small proportion $(<2 \%$ of total referrals) coming from practices in other health boards and directly from hospital specialities.

\section{Study design and population}

An observational cross-sectional study design was applied using data from GP electronic referrals to GCWMS. The dataset was received from GCWMS in February 2016 and included data on the earliest referral per patient from 2012 to 2014 in order to avoid patients appearing more than once. Data cleaning ensured that the included cases were adults (aged 18 years and over), had a diagnosis of obesity (BMI $\geq 30 \mathrm{~kg} / \mathrm{m}^{2}$ ) and had complete data on sex, height and weight. One hundred and forty-six cases $(1.5 \%)$ were excluded in this process. The final dataset comprised 9677 adults with obesity referred from 262 general practices in GGC. The small number of referrals $(<2 \%$ of total referrals) from outside GGC and from specialist services were excluded prior to receiving the data.

\section{Study variables}

Referral, attendance and 'completion'

The main outcome of interest was attendance at weight management, defined as attending at least one group session, after the initial assessment. A further outcome was 'completion', defined as attendance at four or more sessions. This was based on a definition used in a previous published study of the GCWMS. ${ }^{10}$

\section{Patient characteristics}

Patient characteristics included sex, age (grouped into four categories: 18-24 years, 25-44 years, 45-64 years, $65+$ years), socioeconomic status (based on the Scottish Index of Multiple Deprivation 2012 quintiles $^{19}$ ) and BMI (grouped into four categories: $30-35 \mathrm{~kg} / \mathrm{m}^{2}$, $>35-40 \mathrm{~kg} / \mathrm{m}^{2},>40-45 \mathrm{~kg} / \mathrm{m}^{2}$ and $\left.45+\mathrm{kg} / \mathrm{m}^{2}\right)$. Data on comorbidities of the referred patients were incomplete so were not included in the final analysis. There were no data on other variables that may have been of interest, such as ethnicity or smoking status.

\section{Practice characteristics}

Practice characteristics included GP training practice status, practice list size, distance from nearest WMS centre, achievement in the Quality and Outcome Framework 
(QOF) in the year April 2014-March 2015, practice deprivation status and referral rate to the GCWMS.

Data on training practice status were derived from the West Scotland GP training website. ${ }^{20}$ Practice list size was taken from Information Services Division (ISD) Scotland ${ }^{21}$ and divided into three groups: $<4000,4000$ 8000 and $>8000$. Distance from the nearest WMS centre was calculated using GPS mapping software using practice postcode and the postcodes of the 12 WMS satellite clinics that were in operation during the referral period. The three groupings for this variable were under 1 mile, 1-2 miles and over 2 miles. QOF achievement data were taken from the ISD website ${ }^{22}$ and grouped into $<95$, 95-98, 99, 100 points (out of a possible 100 points). Practice deprivation status was based on the percentage of the practice population living in the most deprived $15 \%$ of postcodes and categorised as: $<15 \%, 15 \%-40 \%$ and $>40 \%$ of practice population. Referral rate to GCWMS was per 1000 practice population $(\leq 5,5-10$ and $>10)$.

\section{Statistical analysis}

Descriptive analysis of the study population examined how referral, attendance and completion varied by patient and practice characteristics. Multilevel binary logistic regression models were constructed in order to account for the clustering of patients within practices. Results are presented as univariable (crude) and multivariable (adjusted) ORs and 95\% CIs (95\% CI), with adjustment made for all patient and practice-level characteristics. Analysis was carried out using STATA-MP V.14.0.

\section{Patient involvement}

There was no patient involvement in this study.

\section{RESULTS}

Nine thousand six hundred and seventy-seven adults with obesity were referred to the regional specialist WMS from 262 practices in NHS GGC between January 2012 and December 2014. This is about $4 \%$ of the approximately 260000 adults with obesity estimated to live in NHS GGC. $^{23}$

Table 1 shows the individual-level characteristics of the total GGC population and of the study population (for those referred, attenders (attending at least one session) and 'completers' (attending four or more sessions)). The majority of those referred to the WMS were women, aged 45-64 years and from the most deprived population quintile. The mean age of those referred was 46.5 years (SD 14.3, range: $18-88$ ); the mean BMI was $41.4 \mathrm{~kg} / \mathrm{m}^{2}$ (SD

\begin{tabular}{|c|c|c|c|c|}
\hline & $\begin{array}{l}\text { GGC adult population } \\
\mathrm{N}=924727\end{array}$ & $\begin{array}{l}\text { Referrals } \\
\mathrm{N}=9677\end{array}$ & $\begin{array}{l}\text { Attenders } \\
\mathrm{N}=3250\end{array}$ & $\begin{array}{l}\text { Completers } \\
\mathrm{N}=2252\end{array}$ \\
\hline \multicolumn{5}{|l|}{ Sex ${ }^{*}$} \\
\hline Women & 485629 (52.5) & $6870(71.0)$ & $2331(71.7)$ & $1607(71.4)$ \\
\hline Men & $439098(47.5)$ & 2807 (29.0) & 919 (28.3) & 645 (28.6) \\
\hline \multicolumn{5}{|l|}{ Age groups (years) ${ }^{*}$} \\
\hline $18-24$ & 118069 (12.8) & 694 (7.2) & 118 (3.6) & $66(2.9)$ \\
\hline $25-44$ & $313970(34.0)$ & $3543(36.6)$ & $1006(31.0)$ & 657 (29.2) \\
\hline $45-64$ & 305659 (33.1) & $4369(45.1)$ & $1652(50.8)$ & 1179 (52.4) \\
\hline $65+$ & $187029(20.2)$ & $1071(11.1)$ & $474(14.6)$ & $350(15.5)$ \\
\hline \multicolumn{5}{|l|}{ SIMD 2012 quintile† } \\
\hline Q1-most deprived & 331977 (35.9) & $4778(49.4)$ & $1388(42.7)$ & $922(41.3)$ \\
\hline Q2 & $163677(17.7)$ & $1770(18.3)$ & $600(18.5)$ & $419(18.7)$ \\
\hline Q3 & $133160(14.4)$ & $1254(13.0)$ & $481(14.8)$ & $339(15.2)$ \\
\hline Q4 & 122064 (13.2) & $970(10.0)$ & 368 (11.3) & 265 (11.9) \\
\hline Q5-most affluent & $173848(18.8)$ & $844(8.7)$ & $386(11.9)$ & $290(13.0)$ \\
\hline Missing & - & $61(0.6)$ & $27(0.8)$ & $17(0.8)$ \\
\hline \multicolumn{5}{|l|}{ BMl category $\ddagger\left(\mathrm{kg} / \mathrm{m}^{2}\right)$} \\
\hline $30-35$ & $231182(25 \%)$ & $1232(12.7)$ & $329(10.1)$ & 225 (10.0) \\
\hline$>35-40$ & & 3465 (35.8) & $1152(35.4)$ & 764 (33.9) \\
\hline$>40-45$ & 27742 (3\%) & $2611(27.0)$ & $920(28.3)$ & 658 (29.2) \\
\hline $45+$ & & $2369(24.5)$ & 849 (26.1) & 605 (26.9) \\
\hline
\end{tabular}

*National Records of Scotland Small Area Population Estimates mid-2014. ${ }^{24}$

†Based on estimates from NHS GGC Director of Public Health report 2015-2017. ${ }^{25}$

łBased on estimates from Scottish Health Survey $2014 .^{23}$

BMI, body mass index; GGC, Greater Glasgow and Clyde; NHS, National Health Service; SIMD, Scottish Index of Multiple Deprivation. 
Table 2 Practice characteristics for referrals, attenders and completers, $\mathrm{n}(\%)$

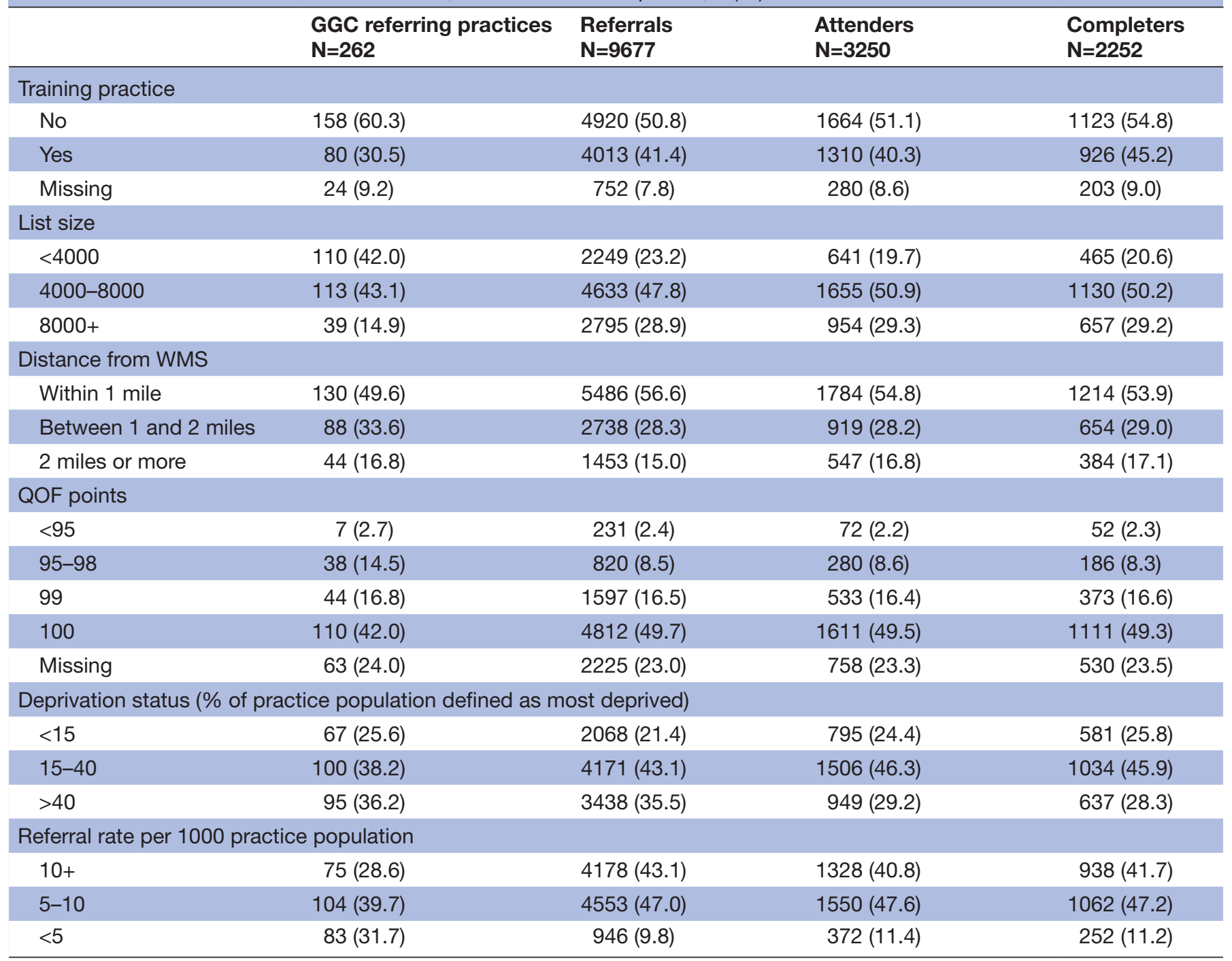

GGC, Greater Glasgow and Clyde; QOF, Quality and Outcome Framework; WMS, weight management service.

6.9, range: 30-97.3). Approximately one-third of those referred attended at least one session $(n=3250,33.6 \%)$; of attenders, $69.3 \%(n=2252)$ completed.

There was a similar picture for those attending the WMS and those attending four or more sessions ('completers'). Over $70 \%$ were women and over half were aged 45-64, with the mean age of those attending 49.8 years (SD 13.5, range: 18-84) and the mean age of 'completers' 50.6 years (13.2, range: $18-83$ ). Over $40 \%$ were from the most deprived population quintile. The mean BMI of attenders was $42.0 \mathrm{~kg} / \mathrm{m}^{2}$ (SD 7.1, range: 30-97.3) and the mean BMI of 'completers' was $42.1 \mathrm{~kg} / \mathrm{m}^{2}$ (SD 7.2, range: $30-97.3)$.

Table 2 shows the distribution of patients by the characteristics of their referring practice, compared with all GGC practices. In GGC, less than one-third of practices were training practices $(n=80,30.5 \%)$. The average list size was 5009 patients (range from 1227 to 16825 ). Roughly half $(n=130,49.6 \%)$ of all practices were within 1 mile of the nearest WMS clinic. The mean number of referrals per practice was 42 (range from 1 to 257), with a mean referral rate of 8.5 per 1000 population (range from 0.7 to 26.3 ).

Just over $40 \%$ of all patients were referred from training practices $(n=4013,41.4 \%)$ and a little under half were from medium-sized practices with list sizes between 4000 and 8000 patients $(n=4633,47.8 \%)$. Over half of patients $(\mathrm{n}=5486,56.6 \%)$ were from referring practices within 1 mile of the nearest WMS clinic. Practices generally scored very highly on QOF, with $66.2 \%$ of patients being referred by a practice that achieved 99 or 100 points out of a possible 100. The characteristics of those attending or 'completing' were broadly similar to those initially referred.

Overall $34 \%$ of those referred actually attended the service, and $2252(23 \%)$ completed by attending for four or more sessions. There were, however, particular groups within the referred population that were more likely to both attend and to complete (table 3). Those aged 65 years and over had a higher attendance rate $(44.3 \%)$, 
Table 3 Profile of service attenders and completers compared with those referred, by patient and practice characteristics, as a percentage of those referred, $n$ (\% of those referred)

\begin{tabular}{llll}
\hline & $\begin{array}{l}\text { Referrals } \\
\mathrm{N}=9677\end{array}$ & $\begin{array}{l}\text { Attendances } \\
\mathrm{N}=3250\end{array}$ & $\begin{array}{l}\text { Completers } \\
\mathrm{N}=2252\end{array}$ \\
\hline Patient characteristics & & & \\
\hline
\end{tabular}

Sex

\begin{tabular}{|llll|}
\hline Women & 6870 & $2331(33.9)$ & $1607(23.4)$ \\
\hline Men & 2807 & $919(32.7)$ & $645(23.0)$ \\
\hline Age group (years) & & & \\
\hline 18-24 & 694 & $118(17.0)$ & $66(9.5)$ \\
\hline $25-44$ & 3543 & $1006(28.4)$ & $657(18.5)$ \\
\hline $45-64$ & 4369 & $1652(37.8)$ & $1179(27.0)$ \\
\hline 65+ & 1071 & $474(44.3)$ & $350(32.7)$ \\
\hline SIMD 2012 quintile & & & \\
\hline Q1-most deprived & 4778 & $1388(29.0)$ & $922(19.3)$ \\
\hline Q2 & 1770 & $600(33.9)$ & $419(23.7)$ \\
\hline Q3 & 1254 & $481(38.4)$ & $339(27.0)$ \\
\hline Q4 & 970 & $368(37.9)$ & $265(27.3)$ \\
\hline Q5-most affluent & 844 & $386(45.7)$ & $290(34.4)$ \\
\hline Missing & 61 & 37 & 17 \\
\hline BMl category (kg/m $\left.{ }^{2}\right)$ & & & \\
\hline 30-35 & 1232 & $329(26.7)$ & $225(18.3)$ \\
\hline$>35-40$ & 3465 & $1152(33.2)$ & $764(22.0)$ \\
\hline$>40-45$ & 2611 & $920(35.2)$ & $658(25.2)$ \\
\hline $45+$ & 2369 & $849(35.8)$ & $605(25.5)$ \\
\hline
\end{tabular}

Practice characteristics

\begin{tabular}{lcll}
\hline Training practice & & & \\
\hline No & 4920 & $1664(33.8)$ & $1123(22.8)$ \\
\hline Yes & 4013 & $1310(32.6)$ & $926(23.1)$ \\
\hline $\begin{array}{l}\text { Missing } \\
\text { List size }\end{array}$ & 744 & 276 & 203 \\
\hline$<4000$ & 2249 & $641(28.5)$ & $465(20.7)$ \\
\hline $4000-8000$ & 4633 & $1655(35.7)$ & $1130(24.4)$ \\
\hline $8000+$ & 2795 & $954(34.1)$ & $657(23.5)$ \\
\hline Distance from WMS & & & \\
\hline Within 1 mile & 5486 & $1784(32.5)$ & $1214(22.1)$ \\
\hline Between 1 and 2 miles & 2738 & $919(33.6)$ & $654(23.9)$ \\
\hline 2 miles or more & 1453 & $547(37.6)$ & $384(26.4)$ \\
\hline QOF points & & & \\
\hline$<95$ & 231 & $72(31.2)$ & $52(22.5)$ \\
\hline $95-98$ & 820 & $280(34.1)$ & $186(22.7)$ \\
\hline 99 & 1597 & $533(33.4)$ & $373(23.4)$ \\
\hline 100 & 4812 & $1611(33.5)$ & $1111(23.1)$ \\
\hline Missing & 2217 & 754 & 530 \\
\hline $\begin{array}{l}\text { Deprivation status (\% of practice population defined as } \\
\text { most deprived) }\end{array}$ & 2068 & $795(38.4)$ & $581(28.1)$ \\
\hline$<15$ & 4171 & $1506(36.1)$ & $1034(24.8)$ \\
\hline $15-40$ & 3438 & $949(27.6)$ & $637(18.5)$ \\
\hline$>40$ & & & \\
\hline
\end{tabular}

Continued
Table 3 Continued

\begin{tabular}{|c|c|c|c|}
\hline & $\begin{array}{l}\text { Referrals } \\
\mathrm{N}=9677\end{array}$ & $\begin{array}{l}\text { Attendances } \\
\mathrm{N}=3250\end{array}$ & $\begin{array}{l}\text { Completers } \\
\mathrm{N}=2252\end{array}$ \\
\hline \multicolumn{4}{|c|}{$\begin{array}{l}\text { Referral rate per } 1000 \text { practice } \\
\text { population }\end{array}$} \\
\hline$>10$ & 4178 & $1328(31.8)$ & $938(22.5)$ \\
\hline $5-10$ & 4553 & $1550(34.0)$ & 1062 (23.3) \\
\hline$<5$ & 946 & $372(39.3)$ & $252(26.6)$ \\
\hline
\end{tabular}

BMI, body mass index; QOF, Quality and Outcome Framework; SIMD, Scottish Index of Multiple Deprivation; WMS, weight management service.

as did those from the least deprived quintile $(45.7 \%)$ and those in the highest BMI category (BMI $45+\mathrm{kg} / \mathrm{m}^{2}$; $35.8 \%$ ). There were a higher proportion of attenders from larger and less deprived practices and from practices further away from weight management centres $(37.6 \%$ attendance from those referred from practices 2 or more miles away). A similar pattern was observed for those completing four or more sessions at the WMS (table 3).

Table 4 presents the logistic regression models of attendance and completion, with individual and practice characteristics, and taking account of clustering within practices. Patient-level characteristics were the strongest predictors of attendance at the specialist WMS, with the odds of attendance increasing with age (OR 4.15, 95\% CI 3.27 to 5.26 for adults aged 65 years and over compared with those aged 18-24 years), BMI category (OR 1.83, 95\% CI 1.56 to 2.14 for those with a BMI $45+\mathrm{kg} / \mathrm{m}^{2}$ compared with BMI $30-35 \mathrm{~kg} / \mathrm{m}^{2}$ ) and increasing affluence (OR $1.74,95 \%$ CI 1.47 to 2.06 for patients from the most affluent practices compared with the most deprived). Men had a lower odds of attendance than women (OR $0.87,95 \%$ CI 0.79 to 0.96$)$.

Practice-level characteristics that were most strongly associated with attendance were being a non-training practice, having a larger list size and having a more affluent patient population. Those patients referred from training practices had a slightly lower odds of attending (OR $0.89,95 \%$ CI 0.81 to 0.99 ) than those referred from non-training practices. Those from a practice with a list size of 4000-8000 were more likely to attend than those from a practice with a list size of under 4000 (OR 1.41, $95 \%$ CI 1.25 to 1.59 ). Similarly, those from a practice with a list size greater than 8000 were also more likely to attend at least one of the weight management appointments following referral (OR 1.29, 95\% CI 1.12 to 1.48). Patients referred from practices serving the most deprived populations (where more than $40 \%$ of the practice population live in the most deprived postcodes) were less likely to attend the WMS (OR 0.82, 95\% CI 0.71 to 0.95 ).

Similar patterns were observed for those who completed a course of sessions at the WMS (table 4), with the same patient-level characteristics the strongest predictors of 'completion'. The likelihood of attending four or more sessions increased with increasing age, such that those aged 65 years and over were almost five times as likely to 


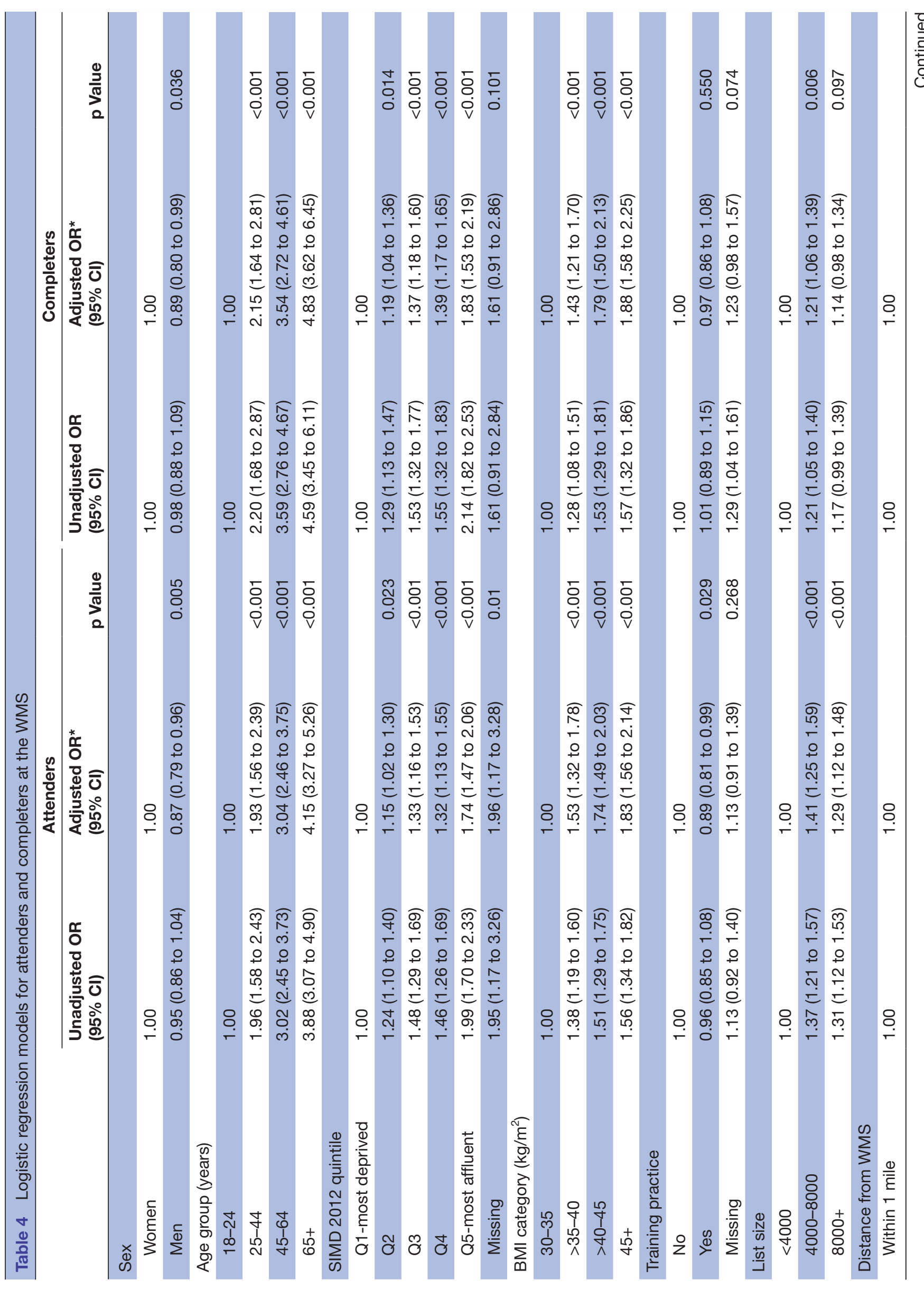




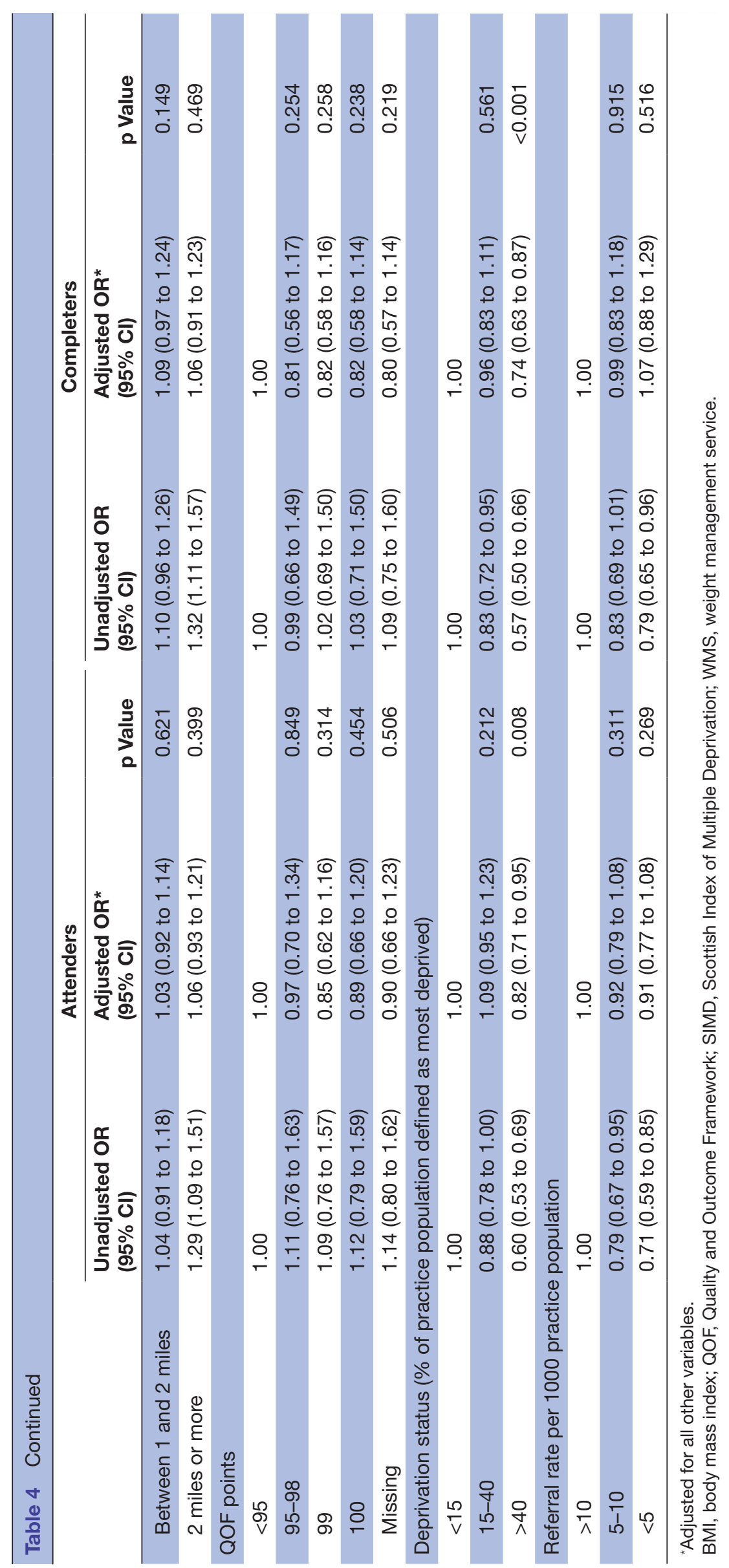


attend four or more sessions compared with those aged 18-24 years (OR 4.83, 95\% CI 3.62 to 6.45 ).

As with attendance, there was a social gradient in 'completing' with increasing odds from the most deprived to the most affluent quintiles (OR 1.83, 95\% CI 1.53 to 2.19 for patients from the most affluent practices compared with the most deprived). Similarly, the odds of attending four or more sessions also increased with each increase in BMI category, with the highest odds being for those from the BMI $45 \mathrm{~kg} / \mathrm{m}^{2}$ and over category (OR $1.88,95 \%$ CI 1.58 to 2.25$)$ compared with the reference group of BMI $30-35 \mathrm{~kg} / \mathrm{m}^{2}$.

\section{DISCUSSION}

\section{Statement of principal findings}

In this observational cross-sectional study of GP referrals to an NHS Health Board specialist WMS, we found that just over one-third of the 9677 adults with obesity who were referred between 2012 and 2014 attended at least one session. There was another marked attrition rate after first attendance, with less than a quarter 'completing' treatment, defined here as attending four or more sessions. Patient-level characteristics were the strongest predictors of attendance and completion, with the odds of attendance increasing with age, BMI category and increasing affluence. Practice-level characteristics most strongly associated with attendance and completion were being a non-training practice, having a larger list size, and not being in areas of extreme deprivation.

\section{Strengths and weaknesses of the study}

There are no previous studies that we are aware of that have explored the predictors of attendance at WMS taking account of both individual patient factors and referring practice characteristics. This study used individual patient-level data and practice-level data to explore predictors of attendance and completion at a specialist WMS, using multilevel binary logistic regression models. As with any secondary data analysis, the quality and validity of the findings are only as good as the quality of the original data. In this case, confidence in the accuracy and consistency of the data is increased as the main outcome variables of interest were referral, attendance and completion, which are reliably recorded.

There were no available data on weight loss outcomes in this study population, which is a limitation. However, previous work conducted in this WMS found that $26 \%$ of those completing phase 1 attendance had lost at least $5 \mathrm{~kg} .^{10}$ Similarly, there were no available data on the total population of adults with obesity in the NHS GGC area, which makes it difficult to comment on the representativeness of the study population. In this study, we used a definition of 'completers' (ie, attending four or more sessions) which is perhaps lower than in some other studies. However, the attrition rate was even greater if the threshold for the number of sessions attended was increased. In addition, higher thresholds for completion tend to be used when describing weight outcomes, rather than being used as an indicator of attendance, as in this study.

\section{Comparison with existing literature}

This study of GP referrals to a large regional WMS found that patient characteristics were more significant predictors of attendance than practice characteristics. This is in keeping with previous research on variation in GP referrals to secondary care services. ${ }^{11}{ }^{12}$ The powerful effect of socioeconomic deprivation-both at the individual level and at the practice level-also resonates with existing literature on barriers to access. ${ }^{26}$

The low level of referral to adult weight management from primary care in this study-roughly $4 \%$ of the approximately 260000 adults with obesity estimated to live in NHS GGC-is similar to previously published studies from the UK. ${ }^{8}{ }^{27}$ The reasons for this low engagement with weight management are multifactorial, including patient, practitioner and health system factors. ${ }^{14-16} 18$

\section{Meaning of the study: possible explanations and implications for clinicians and policy-makers}

This study has highlighted several important issues related to the health service response to obesity. First, the wide variation in referral rates across general practice, despite similar prevalence of obesity, suggests that there is still much to be done to improve engagement with weight management by primary care practitioners. Second, the high attrition rate from referral to attendance and from attendance to completion, at this large regional WMS suggests there are ongoing barriers for patients. Third, the observation that those from the most socioeconomically deprived areas are least likely to attend suggests structural barriers and the need for a more targeted response. Finally, the practice characteristics of quality (as measured by QOF achievement) and distance from the nearest WMS were not associated with attendance in this study, and these negative findings are of interest suggesting that practice quality and proximity are not major drivers of attendance.

This work was based in the largest health board in Scotland, with data available for all referrals made by primary care practitioners based in general practice, between 2012 and 2014. Thus the findings are broadly generalisable to other parts of the NHS and beyond, particularly in terms of gender, age and socioeconomic status; however, there were no data on ethnicity. While Scotland overall has a lower percentage of the population who are from minority ethnic groups-at $4 \%$ overall- this Health Board region has the highest percentage of minority ethnic groups, with the Asian background (defined as Asian/Asian Scottish/Asian British) the largest population group. ${ }^{28}$

\section{Unanswered questions and future research}

The underlying explanation for the observed findings merits further investigation. In terms of patient characteristics, one might hypothesise, for instance, that attendance is more likely for older adults because they are less likely to be working and may be more able to attend appointments 
during working hours. Similarly, it is possible that those adults with a higher BMI may be more motivated to attend as they are experiencing more problems (functional or health-related) as a result of their weight, and may need more support to manage their weight.

With regard to practice characteristics, lower attendance by patients referred from training practices could be related to more referrals done by GP trainees, without perhaps knowing the patient well or fully discussing the implications of referral. Lower attendance from more deprived practices, over and above the effect of individual deprivation status, could point to area-based barriers to attendance such as poorer transport infrastructure or an unwillingness to cross-territorial boundaries. Lower attendance by patients referred from smaller practices is harder to explain and may be related to other confounding factors, such as smaller practices being more likely to be situated in more deprived areas. $^{29}{ }^{30}$ Qualitative research conducted alongside this study may shed more light on these findings. What these findings do indicate is that more work is required to fully understand the role and response of primary care practitioners to obesity management in their practice populations.

Acknowledgements We thank the Glasgow and Clyde Weight Management Service for collaborating with data sharing, and Billy Sloan for help with initial data cleaning. We are also grateful to Paula Barton from NHS Health Scotland for help with the mapping of practices and WMS used to calculate the distance from WMS variable.

Contributors DB, CAO, SM and DM conceived the original idea. DB and PM carried out the statistical analyses. DB drafted the initial manuscript and all other authors contributed to subsequent drafts. All authors read and approved the final manuscript.

Funding This work was supported by DB's clinical academic training fellowship funded by the chief scientist office of the Scottish Government Health Directorate (CAF 13/13).

\section{Competing interests None declared.}

Ethics approval Ethical approval for this study was obtained from the West of Scotland Research Ethics Committee REC5 (Ref: 15/WS/0057).

Provenance and peer review Not commissioned; externally peer reviewed.

Data sharing statement Datasets currently held by lead author, DB, and can be made available on request.

Open Access This is an Open Access article distributed in accordance with the Creative Commons Attribution Non Commercial (CC BY-NC 4.0) license, which permits others to distribute, remix, adapt, build upon this work non-commercially, and license their derivative works on different terms, provided the original work is properly cited and the use is non-commercial. See: http://creativecommons.org/ licenses/by-nc/4.0/

(C) Article author(s) (or their employer(s) unless otherwise stated in the text of the article) 2017. All rights reserved. No commercial use is permitted unless otherwise expressly granted.

\section{REFERENCES}

1. Guh DP, Zhang W, Bansback N, et al. The incidence of comorbidities related to obesity and overweight: a systematic review and meta-analysis. BMC Public Health 2009;9:88.

2. Wang YC, McPherson K, Marsh T, et al. Health and economic burden of the projected obesity trends in the USA and the UK. The Lancet 2011;378:815-25.

3. Whitlock G, Lewington S, Sherliker P, et al. Body-mass index and cause-specific mortality in 900000 adults: collaborative analyses of 57 prospective studies. The Lancet 2009;373:1083-96.
4. Moyer VA. U.S. Preventive Services Task Force. Screening for and management of obesity in adults: U.S. Preventive Services Task Force recommendation statement. Ann Intern Med 2012;157:373-8.

5. National Institute for Health and Clinical Excellence. Obesity. The prevention, identification, assessment and management of overweight and obesity in adults and children, 2004.

6. Swinburn B, Arroll B. Rethinking primary care systems for obesity. Lancet 2016;388:2452-4.

7. Nolan C, Deehan A, Wylie A, et al. Practice nurses and obesity: professional and practice-based factors affecting role adequacy and role legitimacy. Prim Health Care Res Dev 2012;13:353-63.

8. Laws R. Counterweight Project Team. Current approaches to obesity management in UK Primary Care: the Counterweight Programme. $J$ Hum Nutr Diet 2004;17:183.

9. Scottish Intercollegiate Guidelines Network. Management of Obesity. 2010 http://www.sign.ac.uk/assets/sign115.pdf.

10. Logue J, Allardice G, Gillies M, et al. Outcomes of a specialist weight management programme in the UK National Health Service: prospective study of 1838 patients. BMJ Open 2014;4:e003747.

11. Sørensen TH, Olsen KR, Vedsted P. Association between general practice referral rates and patients' socioeconomic status and access to specialised health care a population-based nationwide study. Health Policy 2009;92:180-6.

12. O'Donnell CA. Variation in GP referral rates: what can we learn from the literature? Fam Pract 2000;17:462-71.

13. Foot C, Naylor C, Imison C. The quality of GP diagnosisand referral. The King's Fund. 2010.

14. Epstein L, Ogden J. A qualitative study of GPs' views of treating obesity. Br J Gen Pract 2005;55:750-4.

15. Kim KK, Yeong L-L, Caterson ID, et al. Analysis of factors influencing general practitioners' decision to refer obese patients in Australia: a qualitative study. BMC Fam Pract 2015;16:45.

16. Dewhurst A, Peters S, Devereux-Fitzgerald A, et al. Physicians' views and experiences of discussing weight management within routine clinical consultations: A thematic synthesis. Patient Educ Couns 2017;100:897-908

17. Morrison DS, Boyle S, Morrison C, et al. Evaluation of the first phase of a specialist weight management programme in the UK National Health Service: prospective cohort study. Public Health Nutr 2012;15:28-38.

18. Read S, Logue J. Variations in weight management services in Scotland: a national survey of weight management provision. $J$ Public Health 2016;38:e325-35.

19. Scottish Government. The Scottish Index of Multiple Deprivation: Scottish Government. 2017 http://www.gov.scot/Topics/Statistics/ SIMD/

20. NHS Education for Scotland. General Practice Speciality Training (GPST): West of Scotland. NHS Education for Scotland, 2017. http:// www.westgpst.scot.nhs.uk/home/gpst-programmes/all-practices. aspx

21. ISD ScotlandNHS Scotland. General Practice: ISD Scotland. 2017. http://www.isdscotland.org/Health-Topics/General-Practice/

22. ISD ScotlandNHS Scotland. Quality and Outcomes Framework: ISD Scotland. 2017. http://www.isdscotland.org/Health-Topics/GeneralPractice/Quality-And-Outcomes-Framework/

23. Scottish Government. Scottish Health Survey: Health Board Results, 2012/2013/2014/2015: Scottish Government. 2016.

24. National Records of Scotland. Mid-2014 Population Estimates Scotland 2015 [Available from: https://www.nrscotland.gov.uk/ statistics-and-data/statistics/statistics-by-theme/population/ population-estimates/mid-year-population-estimates/mid-2014.

25. NHS Greater Glasgow and Clyde. Director of Public Health report 2015-2017. Glasgow: NHS Greater Glasgow and Clyde, 2016.

26. Dixon-Woods M, Kirk D, Agarwal S, et al. Vulnerable groups and access to health care: a critical interpretive review. NIHR SDO Programme. 2005. http://www.netscc.ac.uk/hsdr/files/project/SDO_ FR_08-1210-025_V01.pdf.

27. Booth HP, Prevost AT, Gulliford MC. Access to weight reduction interventions for overweight and obese patients in UK primary care: population-based cohort study. BMJ Open 2015;5:e006642.

28. Scottish Government. Ethnic group demographics. 2016. http:// www.gov.scot/Topics/People/Equality/Equalities/DataGrid/Ethnicity/ EthPopMig

29. Mackay D, Sutton M, Watt G. Deprivation and volunteering by general practices: cross sectional analysis of a national primary care system. BMJ 2005;331:1449-51.

30. Wang Y, O'Donnell CA, Mackay DF, et al. Practice size and quality attainment under the new GMS contract: a cross-sectional analysis. Br J Gen Pract 2006;56:830-5. 